\title{
EL HUMANISTA ALONSO DE PROAZA Y LA «MATERIA NUEVA» DE CELESTINA
}

\author{
Jordi Pardo Pastor \\ Universitat Autònoma de Barcelona
}

A mi maestro, Francisco Rico

Hablar sobre Celestina es abrir un debate concerniente a la historia textual y a las lecturas en conflicto que propicia esta obra, además de referimos al difícil problema sobre la autoría de éste o aquel pasaje que integran el corpus textual que el tiempo nos ha conservado. A mi parecer, una de las contrariedades fundamentales al enfrentarnos con tan magna obra es el de la autoría rojasiana en cuanto a lo que se

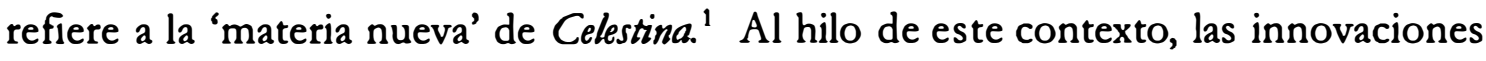
que se producen entre la editio princeps y la edición toledana de 1500 son, básicamente, las más problemáticas.

En 1499, aparece en Burgos una obrilla llamada Comedia de Calisto y Melibea, en dieciséis autos, estampada en los talleres de Fadrique de Basilea, y de la cual falta la primera hoja, donde suponemos comprendía el acostumbrado incipit y el «Argumento General» de la obra. Al año siguiente, surge en Toledo una edición de Celestina que innova considerablemente frente al primer ejemplar que conservamos: hallamos una carta-prólogo «del auctor a un su amigo», unos versos acrósticos en los que «El autor escusándose de su yerro en esta obra que escribió contra sí arguye y compara» y unas octavas rimas finales del editor de la edición, Alonso de Proaza. ${ }^{2}$ Frente a esta añadidura de Burgos 1499 a Toledo 1500, debemos preguntarnos lo siguiente: ¿la editio princeps ya contenía esta 'materia nueva'?, ¿cómo surgió la idea de incluir texto inédito en Celestina?, ¿es realmente Fernando de Rojas el autor de la carta-prólogo y de los versos acrósticos celestinescos? Para Cejador y Frauca está todo más que claro: «¿Quién no ve que el que todo esto hizo fue el mismo Proaza? ¿Envióle el autor de la Comedia todas estas añadiduras o son de Proaza mismo?» ${ }^{3}$ Aunque la cosa no es tan sencilla. 
No debemos, pues, darnos con un canto en el pecho ante la dificultad de tales interrogaciones y su imposible interpretación, ya que hay elementos que, dejando a un lado la 'filología ficción', pueden darnos la llave de esta puerta de siete cerrojos. En primer lugar, debemos tener muy clara cuál es la transmisión textual de la Comedia y sus subsiguientes estadios:

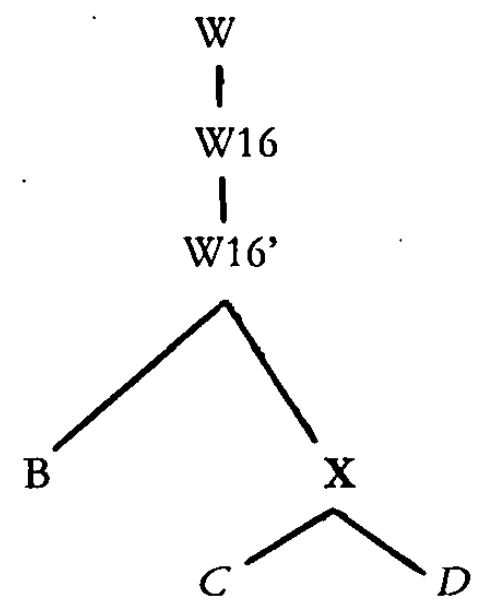

donde $B$ (Burgos 1499), $C$ (Toledo 1500) y $D$ (Sevilla 1501). De esta suerte, observamos en el stemma planteado que del subarquetipo propuesto, $W 16$,' descienden la editio princeps y otro subarquetipo que, siguiendo a Marciales [1985:5], podemos signar como Salamanca 1500. La hipótesis gana peso gracias al colofón rimado que aparece en las octavas rimas finales del corrector Proaza de la edición valenciana de 1514, donde la fecha que hallamos es la de Salamanca 1500. ${ }^{4}$ Este hecho hace suponer que, siendo también Alonso de Proaza el editor de la edición de Valencia 1514, se utilizaron los mismos tipos dactilográficos que en la edición salmantina, que, por lo visto, fue corregida por nuestro humanista y fue la primera edición celestinesca que incluyó la carta-prólogo, los versos acrósticos y las octavas rimas de Proaza, ya que en la editio princeps burgalesa, a mi parecer, es imposible que cupiera tan considerable número de caracteres en tan sólo una hoja.

La tarea editorial de Alonso de Proaza no es, pues, pecatta minutta. Las octavas rimas con las que cierra las ediciones de Salamanca (1500) y Toledo (1500) tienen una doble función: en primer lugar, dar a conocer el sentido de los versos acrósticos que se incluyen en el inicio de la edición y, en segundo lugar, indicarnos, de forma metaliteraria, el modo en que debemos leer la obra. ${ }^{5}$ Es muy frecuente en Proaza, debido a una primera formación escolástico-aristotélica que se verá rectificada mediante las enseñanzas del doctor iluminadísimo, Raimundo Lulio, y su peculiar visión del Arte, la inclusión de materia textual ajena al corpus stricto sensu de la obra in quaestio. En consecuencia, hallamos en las ediciones lulianas quinientistas del cenáculo lulista valenciano, ${ }^{6}$ en el que Proaza, junto a su discípulo Joan Bonllavi, ${ }^{7}$ es la figura más adelantada, añadiduras propias en forma de versos endecasílabos, cartasprólogo y versos pedagógicos. ${ }^{8}$ Exactamente, lo mismo sucede en la edición de las 
Sergas de Esplandián (1510) del regidor Montalvo, donde la inclusión de 'materia nueva' recae en unos colofones rimados al final de la obra que tienen ciertas reminiscencias de las octavas rimas celestinescas y los propios versos acrósticos.

Siguiendo el atinado juicio de Cejador y Frauca, ¿qué sentido tiene la inclusión de unos versos acrósticos que desvelan el nombre y el origen del autor de Celestina, un autor "que quiso celar y encobrir su nombre»? De la misma forma, ¿qué explicación tiene que Fernando de Rojas celara su nombre y, aproximadamente, un año después lo clamara a los cuatro vientos? A mi parecer, frente a los versos acrósticos- y, probablemente, frente a toda la 'materia nueva' de Comedia y Tragicomedia-estamos ante una estratagema del editor.' Así pues, la inclusión de estos versos es inexplicable, como apunta McPheeters sobre los versos laudatorios de la Ars metaphisycalis (1506), y quizá «surgió un problema tipográfico cuando se acabó de imprimir el texto mismo de la obra, porque sobraban todavía bastantes apuntes para los márgenes de varias hojasn. ${ }^{10} \mathrm{Al}$ hilo de este contexto, podemos creer que el editor Juan Gysser, al comprobar que sobraban varias hojas, pidiera al corrector de la impresión que creara unos versos y una epistolilla para llenar el vacío. Del mismo modo, también podemos apostar por una estratagema encauzada a dar un mayor prestigio a la obra con unos versos acrósticos que desvelaran el anónimo y el origen de un autor que "quiso celar y encobrir su nombre», explicándose, posteriormente, mediante unas octavas finales del corrector de la edición. Indistintamente, un camino u otro nos llevan, de forma irremediable, hacia un Alonso de Proaza autor de los versos acrósticos.

Para corroborar esta teoría podemos circular por dos vías paralelas que nos pueden solucionar el acertijo. Debemos prestar atención a las variantes de tradición que se suceden entre las distintas ediciones -Comedia y Tragicomedia- de Celestina, sin dejar de lado, aunque, quizá, en un segundo plano (pero no por ello menos importante), un análisis intertextual entre la obra proaziana incluida en el Cancionero General de Hernando del Castillo ${ }^{12}$ y los versos acrósticos. Siguiendo el criterio impuesto observamos que las diferencias del acróstico se producen entre Comedia y Tragicomedia, entre el subarquetipo $X$ (Salamanca, 1500) y la perdida editio princeps de la Tragicomedia, que siguiendo a Marciales [1985:6] bien podría tratarse de una edición salmantina impresa en 1503, en los talleres de Juan Gysser o bien de una edición de Toledo (1504), del sucesor de Pedro Hagenbach, ${ }^{13}$ donde ya es seguro que hallamos la gran adición distribuida entre los autos XIV y XV de la Comedia. Al tenor de la importancia que suscita la transformación de la obra -y que, a su vez, comporta una evolución del stemma-, creo lícito plasmar la adición stemmática que se produce de Comedia a Tragicomedia: 


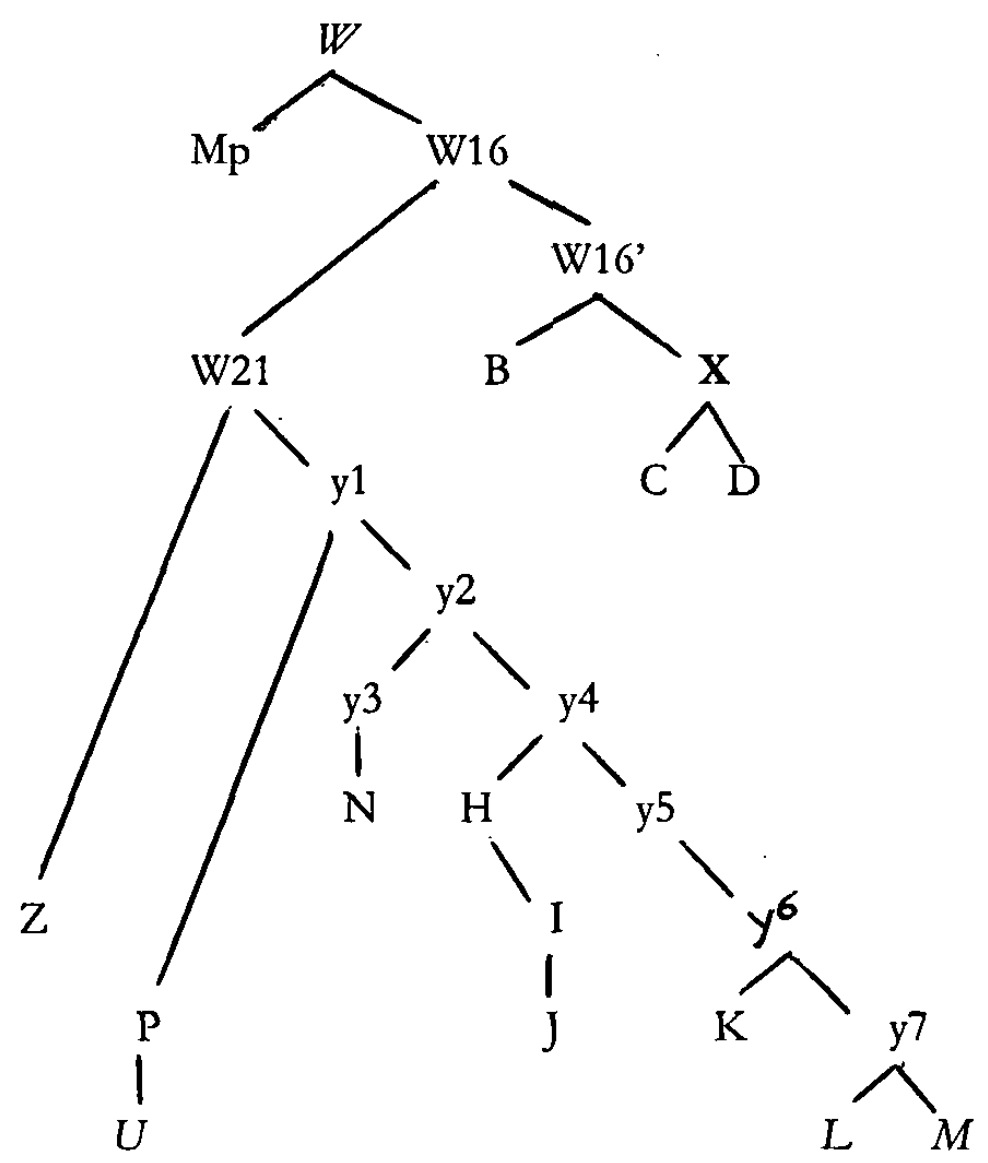

donde, Mp (Manuscrito de Palacio), B (Burgos, 1499), C (Toledo, 1500), D (Sevilla, 1501), Z (Zaragoza, 1507), H (Toledo, 1502 =Toledo, 1510-1514), I (Sevilla, 1502 =Sevilla, 1511), $K$ (Sevilla, 1502 =Sevilla, 1513-1515), $P$ (Valencia, 1514), $J$ (Sevilla, $1502=$ Roma 1515-1516), $U$ (Valencia, 1518), $L$ (Sevilla, $1502=$ Sevilla, 1518), $M$ (Salamanca, $1502=$ Roma, 1520) y $N$ (Roma, 1506, la traducción italiana). ${ }^{14}$

Los cambios que se establecen entre Comedia y Tragicomedia no sön simples errores de imprenta, sino, más bien, innovaciones conscientes por parte de la mano que las desarrolla. Ciertamente, las diferencias se producen en el paso de Comedia a Tragicomedia, del estadio $X$ (Salamanca, 1500) a $W 21$, puesto que $B$ no contenía dicha adición (carta, versos actósticos y octavas rimas). De esta suerte, el subarquetipo de la Tragicomedia es el que transmite la tradición -los errores o innovaciones que pudiera contener este ejemplar-y, a su vez, sufre una contaminación de la edición salmantina perdida, ya que si realmente es ésta la primera impresión en que aparece la 'materia nueva' de la Comedia, forzosamente ha debido suceder una contaminación, teniendo en cuenta que $W 21$ desciende de $W 16$ y suponemos que en este estadio de la tradición aún no se habían incluido ninguna de las adiciones. ${ }^{15}$

Así pues, desde mi punto de vista, las ediciones que se erigen como una especie de epígono retroalimentativo son Salamanca (1500) y Valencia (1514), ambas de Alonso de Proaza -aunque, penosamente, debamos utilizar $C$ en vez del subarquetipo perdido $X$ para cotejar las fuentes. Los cambios más ostensibles, frente a frente, se 
reducen a unos pocos, aunque éstos son los que dan una nueva interpretación lingüístico-semántica al texto. Hallamos, pues, cambios de persona gramatical -de tercera a primera- en la sexta octava; mientras que en la Comedia topamos con "compuso" en la Tragicomedia encontramos "compuse». En la misma octava se producen dos casos similares con «acordó de doran» y «lo más fino oro que vio» y su subsiguiente transformación "acordé de doran" y «lo más fino tíbar que vi con mis ojos" [la cursiva es mía]. A este respecto, los verbos en tercera persona ("compuso", «acordó» y "vio») se refieren a un 'ente' ajeno al personaje que está escribiendo los versos. Claramente, la referencia a una tercera persona tiene como consecuencia que el autor de los versos acrósticos escribe sobre Fernando de Rojas, supuesto autor de los mismos. Podemos llegar a imaginar que, si fuera Alonso de Proaza el autor de dichos versos, hubiera cometido un error categorial al estar pensando en Rojas, aunque también podríamos creer que el mencionado error fuera totalmente deliberado. Frente a este enigma, debemos tener presente que las formas verbales se enmiendan de forma sistemática en el paso de Comedia a Tragicomedia, ya que pueden resultar extravagantes o algo extrañas para el lector de la época, o, quizá, porque el error de Proaza desbarata un tanto la factibilidad de la estratagema editorial que suponen los versos acrósticos. ${ }^{16}$

Las variaciones que se producen en el verso 64 -el paso de «corta: un grande hombre y de mucho valen" a "Cota o Mena con su gran saben- son un tanto particulares ya que no siguen un criterio lógico, sino que, más bien, son una especie de estratagema para dar mayor prestigio a la obra. Recordemos que las menciones a estos dos insignes poetas de nuestra literatura sólo se encuentran en la 'materia nueva' -carta-prólogo y versos acrósticos-, no apareciendo en ningún otro lugar de la Comedia o de la Tragicomedia. Del mismo modo, en variantes como las que se producen en el verso siguiente, sí hallamos un motivo sólido que, siguiendo al profesor Russell, puntualizamos en que «[...] el fuerte hipérbaton "terenciana... obra" molestaba a los lectores de la Comedia.»" Sin embargo, la variante del verso 64 no tiene ningún sentido strictu sensum, aunque, si seguimos la opinión del profesor Rico, podemos aventurar que "corta» sea una trivialización de «Cota», dando mayor sentido al origen o finalidad del cambio. ${ }^{18} \mathrm{~A}$ mi parecer, todos los cambios que se producen entre Toledo (1500) -o su impresión antecesora Salamanca (1500) - y la editio princeps de la Tragicomedia no proceden de la 'máquina impresora' ni de las 'mentes brillantes' de los tipógrafos, sino, más bien, del humanista asturiano Alonso de Proaza que participó en la edición salmantina del 1500 , donde incluyó por primera vez los versos acrósticos, la carta-prólogo que los corrabora y las octavas rimas finales que explican lo anterior. A su vez, pudo ser también el corrector de la edición de Salmanca 1503 impresa de nuevo en los talleres de Juan Gysser, donde Rojas incluye la gran añadidura de los autos XIV y XV, y Proaza perfecciona la 'materia nueva' que ya había estampado tres años antes incluyendo los versos que forman "Concluye el autor, aplicando la obra al propósito por que la acabó» (¿'además del prólogo de la Tragicomedia?).

Al hilo de este contexto, se producen recabadas reminiscencias intertextuales, 
entre los elementos que confeccionan la 'materia nueva' celestinesca. Los versos acrósticos, el «Concluye el autor, aplicando la obra al propósito por qué la acabó» y las octavas rimas que cierran la obra mantienen una perfecta relación retroalimentativa, es decir, las octavas desvelan el sentido de los versos acrósticos, mientras que el "Concluye el autor...» es grosso modo una refundición de la última estrofa de los versos acrósticos tal y como la conocemos en las ediciones de la Comedia. ${ }^{19}$ Del mismo modo, la poesía castellana ${ }^{20}$ de Alonso de Proaza guarda relación temática y conceptual con la materia poética que se añade en las distintas ediciones de Celestina. Así pues, el marcado gusto por los versos trocaicos -hecho que observamos en composiciones como el Romance en loor de Valencia (1505) o la Glosa a Santa Catalina (1511) - es palpable en los versos acrósticos y las octavas rimas finales. Si hacemos balance, hallamos un $52 \%$ de versos trocaicos en el Romance y la Glosa, mientras que en los versos acrósticos estamos entre un $60 \%$ y un $70 \%$, y en las octavas rimas tenemos un $54 \%$ de versos trocaicos. ${ }^{21}$ Este porcentaje relativamente alto de versos trocaicos desvelan un sentido rítmico fundamental del editor Proaza y, a su vez, el arqueo de cifras tan similares, nos acercan un tanto más los versos acrósticos a la pluma creadora del humanista asturiano.

A parte del hecho formal, hallamos reminiscencias temáticas entre la poesía castellana de Proaza y los versos acrósticos celestinescos. Dos son los leitmotiv que se diseminan a lo largo de los versos que forman las composiciones de esta poesía castellana y de los versos acrósticos: las referencias a la Pasión de Cristo, y la alabanza a las civilizaciones clásicas y a sus hombres de letras más laudeados. Este hecho, a mi parecer, confirma una vez más la autoría de los versos acrósticos por parte de Proaza, ya que nuestro insigne humanista es un clérigo ("sacerdotus minimus»), hecho por el cual conocerá a la perfección la Historia Sagrada, y un bachiller en Artes, grado que le enlaza con toda la tradición clásica que ha estudiado. En este sentido, apuesto mucho más por un Alonso de Proaza, clérigo y bachiller en Artes como autor factible de esta 'materia nueva', que por un Fernando de Rojas con origen converso a las espaldas. $^{22}$

Frente a las similitudes temáticas, la Pasión de Cristo se erige como elemento fundamental en la composición de la última octava de los versos acrósticos correspondiente a la edición toledana de 1500. Por otra parte, el «Concluye el auton» es una especie de tour de force entre los versos acrósticos y las octavas rimas del final, ya que estamos ante tres octavas que engloban la cristología expuesta en dichos versos -debido a que son una refundición de la última octava de los versos acrósticos de Toledo (1500) - y en la poesía castellana proaziana, además del fin último de la obra, realzado en las octavas rimas que cierran la mencionada edición toledana. Las correlaciones son bien claras entre el verso 84-89 de los versos acrósticos (Toledo 1500) y los versos 88 y 107-108 de la Glosa del bachiller Alonso de proaza. El leitmotiv de la Pasión de Cristo, se muestra de forma más que explícita en los versos acrósticos y, basándose en referencias a «espinas», «sangre» o el verso «del señor quen cruz murió», en la Glosa. Asimismo, el tono de redención o expiación del pecado a partir de la 
recognoscibilidad de la lascivia es más que paralelo entre "Concluye el auton y la Glosa del bachiller Alonso de proaza. Al hilo de este contexto, hallamos paralelismos formales entre expresiones como: «al que mucho habla sin mucho sentin o «acordó de dorar con oro de lata» - versos 6 y 43, respectivamente, de los versos acrósticos«los leales servidores / por sus servicios leales» o «la gloria de gloria llena»-versos $72-73$ y 125 , respectivamente, de la Glosa-, «a la fin su fin avrá»-verso 10 del Villancico contrabecho por el que dice "Lo que queda tan seguro"- y utan querida de fortuna / de fortuna tan amada) -versos 31-32 pertenecientes al Romance becho por el bacbiller Alonso de proaza en loor de la cibdad de Valencia. Ante estas formas poéticas basadas en la redundancia paralelística, no creo que Rojas, para el que la escritura es «agena de [su] facultad», tuviera la brillantez de crear unos versos tan bien trabados, que se acercan más al usus scribendi del bachiller Proaza que a otra naturaleza. ${ }^{23}$

Potencialmente, la referencia a la pluma es del todo análoga en las composiciones que hasta ahora hemos comentado. Aparece en los versos 13 y $37 \mathrm{de}$ «El autor excusándose» y en el verso 6 - «Por donde respuesta mi pluma aborresce»de la Respuesta del bachiller Alonso de proaza (en referencia a una cuestión propuesta por mossén Crespí). Del mismo modo, en su edición de las Sergas de Esplandián aparece una octava que hace justo medio con los versos acrósticos, las octavas rimas del final de Celestina y con su obra cancioneril:

Aquí se demuestran, la pluma en la mano, los grandes primores del alto decir, las lindas maneras del bien escrebir, la cumbre del nuestro vulgar castellano; al claro orador y cónsul romano agora mandará su gloria callar, aquí la gran fama pudiera cesar del nuestro retórico Quintiliano.

Se demuestra con esta octava la particularidad de Proaza y su gusto por laurear la lengua vulgar castellana, como también hace en los versos acrósticos ひen lengua común vulgar castellana» (v. 68)-, y la devoción hacia la cultura romana, como se observa en todas sus composiciones y, principalmente, en su Romance becho por el bacbiller Alonso de proaza en loor de la cibdad de Valencia. He aquí, pues, el otro motivo recurrente en la poesía de Proaza, y que entronca con su faceta de bachiller en Artes, demostrando su «gran saben en temas mitológicos, históricos y filosóficos. Del mismo modo, la composición en la que observamos, substancialmente, un mayor auge de éste mencionado 'trivium improvisado' es en las octavas rimas finales a su edición toledana de 1500 , en la que participa como «corrector de la impressión» y como tal debe hacer prevalecer su ingenio.

La otra composición en que se centra en la cultura romana es el ya mencionado Romance, donde narra la historia de Valencia, desde el tiempo de los cartagineses 
hasta la conquista de Jaime I y alaba lo «bien regida y gouernada» que se encuentra en estos momentos la ciudad. Así pues, esa pluma tan referida y tan oscura en los versos acrósticos no es otra que la del bachiller Alonso de Proaza que incluyó estos versos en la edición celestinesca de Salamanca 1500 con la total aprobación de su compañero Fernando de Rojas y, que a su vez, modificó y amplió con las adiectio en la Tragicomedia y con el «Concluye el autons. Igualmente, son peculiares los dos primeros versos que conforman el acróstico, ofreciendo una clara alusión al silencio que se autoimpone -como en Otra respuesta del bacbiller Alonso de proaza: «Aunque mi lengua que calla / manda callar como callo" (v. 9-10)-, desvinculándose, quizá, de esta composición propia y otorgándola, a su vez, a otro. ${ }^{24}$

Si forzamos un tanto la máquina interpretativa, logramos deducir diferentes connotaciones temáticas entre los versos y la poesía castellana de Alonso de Proaza que podemos interpretar como recursos propios del poeta. El tema del silencio, como acabamos de ver en el párrafo anterior, es de capital importancia, ya que referencias a la 'reserva' se hacen palmarias en la carta-prólogo -«quiso celar y encobrir su nombre»-, en los mencionados versos acrósticos - «que escuda y suele encubriny en Respuesta del dicho bacbiller-«[...]puesto quel miedo la lengua enmudece» (¿debido, quizá, a que las lenguas «están cortando» al posible autor?). ${ }^{25}$ Junto al silencio, el epíteto "extraño» aplicado a seres incorpóreos o bien inanimados como el «aire» (v. 9) en el acróstico, o en Otra repuesta en los versos 17 y 18: «En peligro mas estraño / es la gloria mas estrañar. A la par, hallamos el hecho de atribuirse la calidad de "flaqueza» a sí mismo en el acróstico «YY así que esta obra a mi flaco entenden-y en Otra respuesta - «yo flaco por que me atierro / si por flaco me desdigo»-. Asimismo, hallamos también en conjunto la idea cristiana de que el cielo es algo positivo y eterno, mientras que la tierra es un valle de lágrimas: «estando en el mundo yacéis sepultados» (v. 79, acróstico) y «Ess seguro y perdurable / sin mudança lo del cielo / y lo más cierto del cielo / todo incierto y variable / Que por dessi mudable / los que mas mas durara / a la fin su fin avrás (v. 4-10, Villancico contabecho). Dicho tema contacta con la imagen de la sepultura, plasmada en la Respuesta del bacbiller Alonso de proaza, «y fueron de herodes cruel sepoltura». En definitiva, he dado hasta aquí diferentes puntos de contacto entre la poesía castellana de Alonso de Proaza y los versos acrósticos celestinescos que, a mi parecer, pertenecen al mismo editor. Las diferentes pruebas que he ido aportando, creo, han servido para desvelar la forma de los versos acrósticos de Celestina y para comprobar las controversias que se producen dentro de la tradición textual celestinesca.

En resumen, la complejidad del tema sobre el que hemos estado hablando nos impide brindar soluciones definitivas y unidireccionales, ya que los elementos con los que trabajamos son mínimos y, en ocasiones, se excluyen unos a otros e, incluso, pueden llegar a contradecirse. Igualmente, creo poder afirmar desde mi modesta posición que no hallamos sentido a la inclusión de esta 'materia nueva' por parte de Fernando de Rojas, por los motivos vistos hasta ahora, y por desvincularse de forma tan radical con su propia obra y con la misma literatura. De esta suerte, la autoría de 
Alonso de Proaza se enclava mucho mejor dentro del gran 'enigma' que supone la obra en sí, además de otorgar lógica a las composiciones in quaestio. Del mismo modo, el tema tratado en estas páginas no queda del todo agotado, erigiéndose la figura del humanista español Alonso de Proaza como 'materia' de estudio dentro de las letras españolas. Doctores tiene la escuela.

\section{****}

\section{NOTAS}

' Con dicho calificativo doy a entender todas las añadiduras que se suceden en las diferentes impresiones quinientistas y que están cercanas a la voluntad del autor, además de metamorfosear la obra en un producto nuevo. Sobre la tradición textual de Celestina es interesante consultar: K. Whinnom, «The Relationship of the Early Editions of the Celestina), Zeitschrift für Romanische Pbilologie 82 (1966): 29-39; M. Marciales, ed. Celestina. Tragicomedia de Calisto y Melibea, Illinois, U Illinois P, 1985; José Fradejas, «Cinco siglos de historian, en Diario Córdoba. Cuadernos del Sur (9 de diciembre de 1999): 8-9; F. J. Lobera Serrano, "La Celestina: Redacciones, testimonios y ediciones modernas», (impreso por el autor), 23 pp.; J. O'Neill, Celestina 1499-1999. A Checklist of Editions, Translations, and Adaptations in the Library of The Hispanic Society of America, New York: HSA, 1999.

${ }^{2}$ Sobre la figura del humanista Alonso de Proaza remito al lector a $M$. Menéndez y Pelayo, Origenes de la novela (Santander, 1943), III: 227-230; F. Vindel, El arte tipográfico en España durante el siglo XV (Madrid, 1946), IV: 207; C. Penney, The Book Called Celestina (New York: The Hispanic Society of America, 1954), pp. 15-16; D. W. McPheeters, El bumanista español Alonso de Proaza (Valencia: Castalia, 1961); J. Cejador y Frauca, ed. La Celestina (Madrid: Espasa-Calpe ("Clásicos Castellanos»), 1972"10, p. XV y ss; P. Botta, «El texto de la Celestina en la edición de Valencia 1514m, en Tragicomedia de Calisto y Melibea (Valencia, Juan Joffre, 1514). Estudios y edición paleográfica (Valencia: Institut Alfons el Magnànim, 1999), pp. 17-29; J. L. Canet, «Alonso de Proaza», en Tragicomedia de Calisto y Melibea (Valencia, Juan Joffre, 1514). Estudios y edición paleográfica (Valencia: Institut Alfons el Magnànim, 1999), pp. 31-38; y, por último, J. Pardo, «Alonso de Proaza, 'homo litterarum, corrector et excelsus editor'» en Convenit. Selecta-3, Porto, e-dition - Editora Mandruvá: http://www.hottopos.com (Gabinete de Filosofia Medieval da Facultade de Letras da Universidade do Porto), 2000.

${ }^{3}$ Cejador y Frauca, p. XV.

${ }^{4}$ «El carro phebeo despues de auer dado / mill \& quinientas bueltas en rueda / ambos entonces los hijos de Leda / a phebo en su casa tenien possentado: / quando este muy dulce y breue tratado / despues de reuisto \& bien corregido / con gran vigilancia puntado y leydo / fue en Salamanca impresso acabado.) (Tragicomedia de Calixto y Melibea, Valencia, 1514, fol. 70r).

${ }^{5}$ En la octava «Dice el modo que se ha de tener leyendo esta comedia» Alonso de Proaza informa de la manera en que debemos de leer la obra para incidir en el pathos del oyente. Proaza, de esta manera, está catalogando el género de Celestina, cosa que posteriormente el autor del Prólogo ('materia nueva' que sólo hallaremos en la Tragicomedia) ratificará. En esta octava se establece que la obra será leída en una asamblea reducida, 
por un recitator que representará de la mejor forma posible todos los personajes o papeles. Podemos deducir por estas palabras y por los escolios al teatro de Terencio efectuado por Enrique de Villena que predominaban, en obras como Celestina, las lecturas dramáticas. Este factor puede relacionar la obra de Rojas con las comedias de Terencio y, en definitiva, con el género de la comedia romana. Sobre este tema remito calurosamente al lector a $\mathrm{E}$. J. Webber, "The Literary Reputation of Terence and Plautus in Medieval and Renaissance Spain", Hispanic Review 24 (1956): 191-206; C. Morón Arroyo, Sentido y forma de "La Celestina" (Madrid: Cátedra, 1974); P. M. Cátedra, «Escolios teatrales de Enrique de Villena», en Serta philologica F. Lazaro Carreter, II (Madrid, 1983), pp. 127-136; Luis Gil, "Terencio en España: del medioevo a la ilustración", en Estudios de bumanismo y tradición clásica (Madrid, 1984); P. Taravacci, Osservazioni sulla teatralità della "Celestina" (Pisa: Giordini Editori, 1985); M. E. Lacarra, Cómo leer la «Celestina» (Barcelona: Júcar, 1990); R. Beltrán, "Cuatro escenas de comedia en La Celestina y la celestinesca: filiación genérica de la acción dramática», en Butlleti de la Societat Castellonenca de Cultura 74 (Enero-Junio 1998) [= Cultura i bumanisme en les lletres hispàniques (s. XV-XVI), ed. G. Colón y Ll. Gimeno], Pp. 213-234; F. B. Pedraza, «La integridad dramática», en Diario Córdoba. Cuadernos del Sur (9 de diciembre de 1999), pp. 30-31.

${ }^{6}$ Entre las ediciones lulistas proazianas contamos con la Ars methaphysicalis (1506) y el Officium gloriosissimi et beatissimi martyris Raymundi Lulli (1506), donde colabora con su maestro Jaume Janer; la Disputatio Raymundi et Hamar Sarraceni (1510), en la cual se incluyen los Disputatio quinque hominum sapientium, Liber de accidente et substantia, Liber de demonstratione per aequiparantiam y Sententia definitiva, el Logica Nova (1512), que contiene además los Liber de ascensu et descensu intellectus y Liber correlativorum innatorum; y el Ars inventiva veritatis (1515), donde hallamos, también, traducciones del catalán al latín de las obras del mismo Lulio, la Taula general y el Art de fer e solre questions, con el nombre de Tabula generalis y Lectura super artem inventivam et tabulam generalem. Sobre las ediciones lulianas es fundamental el trabajo de E. Rogent y E. Duran, Bibliografia de les impressions lul-lianes (Barcelona: Institut d'Estudis Catalans, 1927).

${ }^{7}$ Sobre la figura del discípulo de Alonso de Proaza, Joan Bonllavi, es conditio sine qua non consultar los trabajos de Rogent y Duran [n6], pp. 69-70; R. Guilleumas y J. M². Madurell, «La biblioteca de Joan Bonllavi», Revista valenciana de filologia 4 (Enero-Marzo 1954); B. Schnid, Les «traduccions valencianes» de Blanquerna (València 1521) i de la Scala dei (Barcelona 1523). Estudi lingüistic (Barcelona: Curial, 1988); A. Soler, «Joan Bonllavi, lul•lista i editor eximi», dentro de Estudis de llengua i literatura catalanes / XXXI. Miscel-lània Germà Colón (Barcelona: Publicacions de l'Abadia de Montserrat, 1995), pp. 125-150.

${ }^{8}$ En cuanto a la 'materia nueva' de las ediciones lulistas en las que Proaza colabora hallamos, como composiciones más significativas, unos versos laudatorios, Carmen endecasyllabum in laudem Artis Raymundi Lulli y unos versos dirigidos al lector, Alphonsus de proaza ad lectorem, en la Ars methapbysicalis (1506); del mismo modo, en el Liber de Logica Nova (1512) hallaremos una carta, la Joanni Bonlabii Epistola, dirigida a su discípulo.

${ }^{9}$ A este respecto, véase J. R. Stamm y su estudio La estructura de La Celestina. Una lectura analitica (Salamanca: Universidad, 1988). Hallaremos un amplio apartado, «El marco textual», donde Stamm hace una detallada disquisición sobre la 'materia nueva' celestinesca, apuntando la posibilidad de una estratagema editorial en cuanto a los versos acrósticos (pp. 20-23).

1" McPheeters, El humanista español [n2], p. 126. 
" «La historia de los primitivos talleres de imprenta en Salamanca es bastante oscura debido al anonimato de sus impresores. Norton nos cuenta que de los más de 100 libros impresos alli en el siglo XV, sólo cuatro llevan el nombre de algún impresor. Tres están firmados por Leonardus Alemanus y Lupus Sanz; el cuarto fue la primera obra de un taller establecido por Hans Gysser en 1500) (Colin Clair, Historia de la Imprenta en Europa [Madrid: Ollero \& Ramos, 1998], p. 118). Creo conditio sine qua non citar cierta bibliografia, aunque no con la finalidad de ser exhaustiva, sobre la imprenta y, en particular, sobre el arte tipográfico en la Península Ibérica: Pierce Butler, The Origin of Printing in Europe (Chicago, 1940); G. Dowding, An Introduction to the History of Printing Types (London, 1961); F. Vindel, El origen de la imprenta en España (Madrid, 1935); J. Madurell y J. Rubió, Documentos para la bistoria de la imprenta y librería en Barcelona (Barcelona, 1955); P. Bohigas, El libro español (Barcelona, 1962); F. J. .Norton, Printing in Spain, 1501-1520 (Cambridge: Cambridge UP, 1966).

${ }^{12}$ El texto poético de Proaza será citado por la magistral edición de Brian Dutton, El cancionero del siglo XV, Biblioteca española del siglo XV (Salamanca: Universidad, 1991), volúmenes V y VI (véase en el volumen ú́ndice» p. 420). En cuanto a los cancioneros y cancioneros de autor véanse los pertinentes estudios de $\mathrm{V}$. Beltrán: «El caso de Jorge Manrique», en Historia y ficciones. Coloquio sobre la literatura del siglo XV, ed. R. Beltrán, J. L. Canet y J. L. Sirera (Valencia: Universidad-Departamento de Literatura Española, 1992), pp. 167-188; «La organización de los materiales», en Poetry at Court in Trastámaran Spain, ed. M. Gerli y J. Weiss, (Tempe, AZ: Medieval and Renaissance Texts \& Studies, 1998), pp. ; «Dos Liederbätter probablemente autógrafos de Juan del Encina y una posible atribución», Revista de Literatura Medieval 7 (1995): 41-71; «Las grandes compilaciones y los sistemas de clasificación», Cultura Neolatina 55 (1995): 233-265; «Dreg de natura Matfre Ermengaut y el Cancionero de Charles de Orléans», Romania 115 (1997): 193-206; «Juan Fernández de Hijar y los cancioneros por adición", Romance Pbilology 50 (1996): 1-19; «Tipología y génesis de los Cancioneros. Cancioneros de auton», Revista de Filología Española 78 (1998): 49-101.

${ }^{13}$ «[...] en 1498, se estableció en Toledo el taller de Pedro Hagenbach, que ya había trabajado con anterioridad en Valencia y llegó a Toledo probablemente por invitación de Melchior Gorricio, que proporcionó el capital para los libros de Hagenbach de 1498 que se conservan. Hagenbach disfrutó también del mecenazgo del arzobispo de Toledo, el futuro Cardenal Jiménez de Cisneros, para el que publicó en 1499 un Misal Mozárabe a petición del arzobispo y a expensas de Gorricio" (Colin Clair [n11], p. 117). Estuvo asociado con Leonardo Hutz, con quien acabó de imprimir en Valencia, a expensas de Jacobo de Vila, el cuaderno de Furs nous fets per lo cri | stianissim e molt alt senyor | Rey don Ferrando Rey de Castilla e de | arago e de valencia (1493). Pedro Hagenbach fue, también, el impresor de la ya citada edición Toledo (1500). En cuanto a Leonardo Hutz fue un impresor bastante reconocido en la época y en sus primeros escarceos trabajó con Jorge Coci que «en septiembre de 1499 firmó un Breviario de la Orden de los Jerónimos junto con Leonardo Hutz y Lope Appentegger (sobrino de Pablo Hurus)" (Colin Clair, 254). A partir del año 1500, «carecemos de noticias positivas de Leonardo Hutz; lo cual ha hecho pensar a algunos bibliógrafos que pudiera ser el mismo que con el nombre de Leonardo Alemán imprimió en Salamanca, asociado con Lupus Sanz de Navarra [...] (J. E. Serrano y Morales, Diccionario de las imprentas en Valencia [Valencia, 1898], p. 222). De esta suerte, Leonardo Hutz fue el impresor de la Oratio luculenta de laudibus valentiae (1505) de 
Alonso de Proaza, estableciéndose a partir de este momento en Valencia, editando obras del corrector Proaza como la Ars metaphisycalia (1506) del beato Raymundo Lulio.

${ }^{14}$ Sobre la disposición stemmática de Celestina véase $\mathrm{F}$. J. Lobera, «La transmisión textuab), en Fernando de Rojas (y Antiguo Autor), La Celestina. Tragicomedia de Calisto y Melibea, ed. dirigida por Francisco Rico (Barcelona: Crítica, «Biblioteca Clásica», 2000), p. CXCIII y ss.

${ }^{15}$ De acuerdo con Marciales (Celestina. Tragicomedia de Calisto y Melibea [Urbana, Illinois: U Illinois $P, 1985]$, p. 5-8), postulo que $W 21$ se refiere, como ya hemos dicho, a las ediciones perdidas de Salamanca (1503) o Toledo (1504), aunque soy más partidario de la edición salmantina de 1503, costeada, seguramente, por Juan Gysser que participó como impresor en la edición perdida de Salamanca (1500), y que, según Marciales, contiene ya todas las adiciones mayores y menores, y, posiblemente, la gran adición que transforma la obra de dieciséis autos a veintiuno. De esta suerte, sobre esa fecha hay constancia de que Proaza residía en Salamanca, con lo que hubiera sido muy fácil para un «editor trashumante» como él participar en esta impresión salmantina, corrigiendo todo aquello que produjera confusiones en el lector. Asimismo, la Tragicomedia tiene otras peculiaridades frente a la Comedia: aparecen, por primera vez, un Prólogo y unos versos finales, «Concluye el autor, aplicando la obra al propósito por que la acabón, que son, prácticamente, un calco de las octavas rimas del corrector Proaza y de los versos acrósticos que encabezan la obra. Así pues, con tres años de diferencia, surgen en el mismo taller dos ejemplares totalmente diferentes de Celestina -Comedia y Tragicomedia- que están revisadas por el mismo corrector, Alonso de Proaza, y que, a su vez, siguen un mismo criterio: la añadidura de inédita 'materia nueva'. De este modo, creo poder explicar la contaminación que sufre la editio princeps de la Tragicomedia del subarquetipo $X$, ya que tal como se presenta el stemma es un tanto imposible que la tradición de la Tragicomedia contuviera la 'materia nueva' que encontramos en la Comedia. Por lo tanto es, quizá, posible' que el texto salamantino de 1503 se hubiera creado a partir de una edición de la Comedia de Salamanca 1500 y las nuevas añadiduras que sufre la tradición de la Tragicomedia.

${ }^{16}$ Sobre las variaciones textuales que se producen en los versos acrósticos entre Comedia y Tragicomedia, véase el artículo ya citado [n2], «Alonso de Proaza, "homo litterarum, corrector et excelsus editor'», donde incluyo una edición crítica de los versos acrósticos siguiendo las ediciones proazianas de Toledo (1500) y Valencia (1514).

${ }^{17}$ P. E. Russell, ed. Comedia o Tragicomedia de Calisto y Melibea (Madrid: Castalia, 1991), p. 192, n21.

${ }^{18}$ No obstante, ante esta hipótesis debemos tener en cuenta, como dice Russell (192 n23), que Rodrigo Cota no murió hasta el año 1505 y que la edición de la que hablamos se imprime en el año 1500, apareciendo en el penúltimo verso de la octava siguiente, «al cual Jesucristo reciba en su gloria», la idea de que dicho «Antiguo Aucton» está muerto en el momento en que son editados y/o elaborados los versos acrósticos. Sobre la relación entre Rodrigo Cota y Celestina véase: $H$. Salvador Martínez, "Cota y Rojas: contribución al estudio de las fuentes y autoría de La Celestina ", Hispanic Review 48 (1980): 37-55.

${ }^{19}$ Debemos tener en cuenta que en el paso de Comedia a Tragicomedia, una de las variatio más importantes es la transformación que sufre la última estrofa de los versos acrósticos:

Olvidemos los vicios que así nos prendieron, 


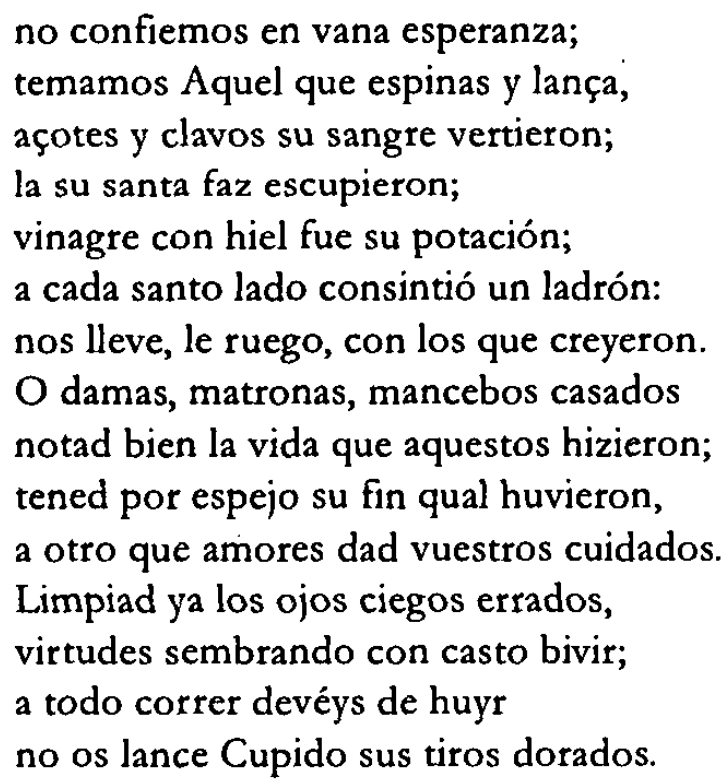

Como podemos observar, la piadosa alusión a la Pasión de Cristo queda eliminada y se ve sustituida por una octava que se limita a reafirmar el propósito moralizador de la obra. Dentro de esta modificación, podemos observar que el verso 4 correspondiente a la Tragicomedia es una alusión a Juan de Mena, a la copla 107 de La coronación del marqués de Santillana, donde Macías manifiesta su desengaño amoroso.

20 Alonso de Proaza, aparte de sus composiciones poéticas en lengua latina para las ediciones lulistas del cenáculo valenciano, tiene en su haber poesías «en lengua vulgar castellana» que se remontan en un primer origen a las octavas rimas de Celestina y a la Oratio luculenta (1505) impresa en los talleres de Leonardo Hutz. Asimismo, hallamos composiciones de Proaza en el Cancionero General de Hernando del Castillo impreso en 1511 y alguna que otra modificación en los versos de la reimpresión de 1514. Del mismo modo, en la edición proaziana de las Sergas de Esplandián (1510), observamos una serie de octavas, como hemos apuntado más arriba, muy similares a las octavas rimas celestinescas, tanto en temática como en estructura métrica formal.

21 Sobre la cuestión métrica de la poesía castellana proaziana, véase McPheeters [n2], p. 45 y ss., donde hace un perfecto análisis de cada una de las composiciones castellanas de Alonso de Proaza, ya en lo que se refiere a los aspectos externos (métrica, tipo de estrofa, tipo de versos...), ya a cuestiones temáticas y/o estilísticas.

${ }^{22}$ Indagando en la vida de Rojas observamos que el estigma de la herejía es una constante dentro de su entorno familiar. El padre de Fernando de Rojas, Hernando de Rojas, fue condenado por judaizante en 1488; otros documentos de la época nos indican que su suegro, Álvaro de Montalbán, fue procesado dos veces por la Inquisición toledana, en 1480 y en 1525 . Éste propuso en el pleito que se realizó en el año 1525 como defensor a «el Bachiller Rojas, que escribió Melibeas. Su candidatura es recusada por los inquisidores alegando el no estar limpio de sospecha y su poca fiabilidad; la Inquisición «le dixo que no ay lugar, e que nombre persona sin sospechan. Asimismo el testamento de Rojas es el testimonio más atrayente para respaldar esta idea sobre la importancia de lo judaizante en el autor y en su obra. En este inventario de sus bienes se nombra a sus hijos, hijas y yernos, todos ellos de linajes conversos. Rojas murió en 1541 como cristiano, aunque un crítico como S. Gilman nos dibuja, quizá exagerando un poco, a un Rojas moribundo 
deseando despedirse de la vida según la costumbre judaica, pero obligado en un último acto de hipocresía a aparentar una muerte cristiana para que su familia no tuviera problemas con los inquisidores (The Spain of Fernando de Rojas: the Intellectual and Social Lanscape of 'La Celestina" [Princeton: Princeton UP, 1972], pp. 483-486).

Lo que voy a citar a continuación es una bibliografía sobre la figura de Rojas que no pretende, ni mucho menos, ser completa: M. Serrano Sanz, «Noticias biográficas de Fernando de Rojas, autor de La Celestina, y del impresor Juan de Lucenan, Revista de Archivos, Bibliotecas y Museos 6 (1902): 245-299; F. del Valle Lersundi, «Documentos referentes a Fernando de Rojas», Revista de Filologia Española 12 (1925): 385-396, y 17 (1930): 183; F. del Valle Lersundi, "Testamento de Fernando de Rojas, autor de La Celestina», RFE 16 (1929): 366-388; O. H. Green, «Fernando de Rojas 'converso' and 'hidalgo'», Hispanic Review 15 (1947): 384-387; N. López Martínez, Los judaizantes castellanos y la Inquisición en tiempo de Isabel la Católica (Burgos, 1954); Ivy A. Corfis, «Fernando de Rojas and Albrecht von Eyb's Margarita poetica), Neopbilologus 68 (1984): 206-213; N. Salvador Miguel, «El presunto judaísmo de La Celestina», en The Age of the Catholic Monarchs 14741516, Literary Studies in Memory of Keith Whinnom, ed. A. Deyermond \& I. Macpherson, Bulletin of Hispanic Studies, Special Issue (1989): 162-177.

${ }^{23} \mathrm{El}$ usus scribendi de Alonso de Proaza está más que contaminado por la manera de poemar de Juan de Mena. Así pues, en las octavas rimas finales, las referencias a "Orfeo» y al «triste Plutón» fueron sugeridas por una lectura del Laberinto de fortuna. De esta suerte, Cejador afirma que Proaza copiaba indecorosamente a Mena (II: 215), mientras que Cabañas le acusa de plagio aunque admite que la estrofa del Laberinto «hizo fortuna» (F. Castro Guisasola, Observaciones sobre las fuentes literarias de 'Ta Celestina" (Madrid, 1924], p. 166).

${ }^{24}$ ¿A un Fernando de Rojas negado para la composición poética? A un «Sabio de sabios abrigo / dol claro saber se abriga / perseguidor y enemigo / de ignorancia su enemiga. / Porque quiere siendo digno / de la victoria más digna / que la falta del indigno / se publique por indigna. / Aunque mi lengua calla (...)» (vv. 1-9) como afirma en su Otra respuesta del bachiller Alonso de proaza.

${ }^{25}$ En la tercera octava del acróstico, se hace referencia al disfavor que sufre el autor de los versos acrósticos, que pensaba «cobrar más honon, y al que las malas lenguas están "cortando», debido a «los daños de envidia y murmuros». ¿Es posible que Proaza se excusara (como el propio nombre de los versos acrósticos indica, refiriéndose, quizá, a la obra -como versos acrósticos- escribiéndola contra sí debido a que debería guardar el «secreto» de autoría) de antemano por sí alguien descubriese la estratagema editorial del acróstico? 